\title{
A Modern Approach to the Formation of a Terminological System in the Field of Fire Protection
}

\author{
Yuriy Naumov ${ }^{1}$, Nikolai Smirnov ${ }^{1}$, Andrei Pekhotikov ${ }^{1}$, Ol'ga Zuban', and Marina \\ Gravit $^{2 *}$ \\ ${ }^{1}$ FGBU VNIIPO EMERCOM of Russia, 143903, VNIIPO district, 12, Balashikha, Moscow Region, \\ Russia \\ ${ }^{2}$ Fire Safety Department, Peter the Great St. Petersburg Polytechnic University, 195521 \\ Polytechnicheskaya, 29, Saint-Petersburg, Russia
}

\begin{abstract}
The paper considers a variant of combining the terms used in the field related to the study of fire protection means into a terminological system. The correct definition of terms is also crucial in technological and manufacturing processes. That is why it was decided to form and describe the terminological system in the field of fire protection and fire retardant materials. The terms in terminological system are to be related between each other, and to be expressing the relationship between the concepts that they denote. Such a system does not yet exist in the field of fire protection, so the authors aim was to create its basis. The types of relations between the terms defining the structure of the system have been established, a diagram that illustrates the distribution and coordination of terms in the system has been developed. On the basis of the relations between the terms established in the terminological system, the existing definitions were assessed with subsequent, if necessary, adjustments to meet the requirements for the terms of unambiguity, compliance with the expressed concept and elimination of synonymy.
\end{abstract}

\section{Introduction}

The consistency, clarity and accuracy of the presentation of information inherent in the language of science is largely associated with the wide use of words and phrases of a terminological nature. There is currently no consensus on what a scientific and technical term is, however, it is generally accepted that it performs along with the nominative also the definitive function [1]. In other words, the feature that determines the scientific and technical term is the expression of the concept of a special area of knowledge [2].

In the semantic aspect, the following basic requirements are imposed on the term:

- unambiguousness of the term;

- correspondence of the meaning of the term to the expressed concept;

\footnotetext{
*Corresponding author: marina.gravit@mail.ru
} 
- full meaning, which is understood as the reflection in the meaning of the term of the minimum number of features sufficient to identify the designated concept;

- consistency, which means that the term should be an element of an interconnected system of terms.

Requirements for a term operate within a specific system of terms, called a terminological system, which is usually understood as a set of terms with fixed relations between them, expressing the relationship between the concepts that they denote. Relationships between concepts are expressed by various types of connections: generic, partitive, associative.

The terminological system in the scientific field related to the development of fire protection means and technologies for their application has not yet been created. The terms expressing the basic concepts in this area contain technical regulations, standards, methodological documents, dictionaries and encyclopedias of various directions. The amount and composition of terms presented in each of these documents are determined by the content of the document, and therefore their amount is limited, and the composition is disordered. At the same time, as a rule, the definitions of terms contained in different documents are not consistent with each other, and the links between the terms have not been established. The consequence of this is the ambiguity in the definitions of terms and synonymy in the designation of concepts, indicating non-observance of the requirement for the unambiguity of the term, according to which in the terminological system each term should express only one concept and, conversely, one concept should be expressed by only one term [3].

\section{Materials and methods}

Modeling a system of concepts usually includes the following operations [4]:

- selection of the conceptual field, preliminary concepts to be processed taking into account the subject area;

- analysis of the content and scope of each concept;

- definition of relations and the position of these concepts in the system of concepts;

- illustration of the resulting system of concepts using a concept diagram;

- formulation and evaluation of definitions of concepts based on the relationship between them;

- assigning a designation to each concept.

The basis of the terminological system presented in the article was formed by the concepts widely used in the field of fire protection, to which, in order to give the system a clear structure and logical completeness, new ones were added (constructive method of fire protection, combined method of fire protection [5-7]). As a way of combining the concepts that make up the conceptual field, we used relations similar to those established in the classification of fire protection means by composition and properties. Such relationships are of the generic type. The generic concept in this case will be the concept of "fire protection means", which is the basis of the classification. In order to give a definition of the term expressing this concept, it is necessary to consider the characteristics that make up its essence. Fire protection means are considered as a separate type of product, the purpose of which is to reduce the fire hazard of the protected object [8-11]. The sign that distinguishes them from other similar types of products, the use of which is possible for a similar purpose, for example, building materials, is that this is their direct and only purpose. This is related to the differences in the fire safety requirements for these types of products and the methods of their testing. From the point of view of ensuring fire safety requirements, the condition for the use of building materials is compliance with the requirements that apply directly to these materials, while fire protection means must ensure a reduction in the fire hazard of the structures or materials protected by them. The term "fire retardant efficiency" is used to refer to this effect. Taking into account the above, the following wording can be proposed to define 
this term: "a fire protection means is a substance, a mixture of substances (composition) or a material that has fire retardant efficiency and is designed to reduce the fire hazard and / or increase the fire resistance of the protected object." In this formulation, the definition also contains information about the composition of the concept of "fire protection means", indicating that it refers to fire retardants, compositions and materials. In turn, fire retardants are subdivided into fire retardant varnishes and paints, impregnating compounds, greases and pastes, and combined compositions [12-15].

\section{Results and discussion}

Each of the listed types of fire protection means has features of application technology, and the means of protection obtained as a result of their application to structures and materials also differ [16-18]. This allows to group concepts related to the stages of production, use and operation of one type of fire protection means, with the establishment of relations between them. Such relationships are of the associative type.

Thus, the formed system of concepts has a mixed system of relations obtained by combining generic and associative types of relations. The distribution of terms in the system in accordance with the relationships established between them is shown in Figure 1.

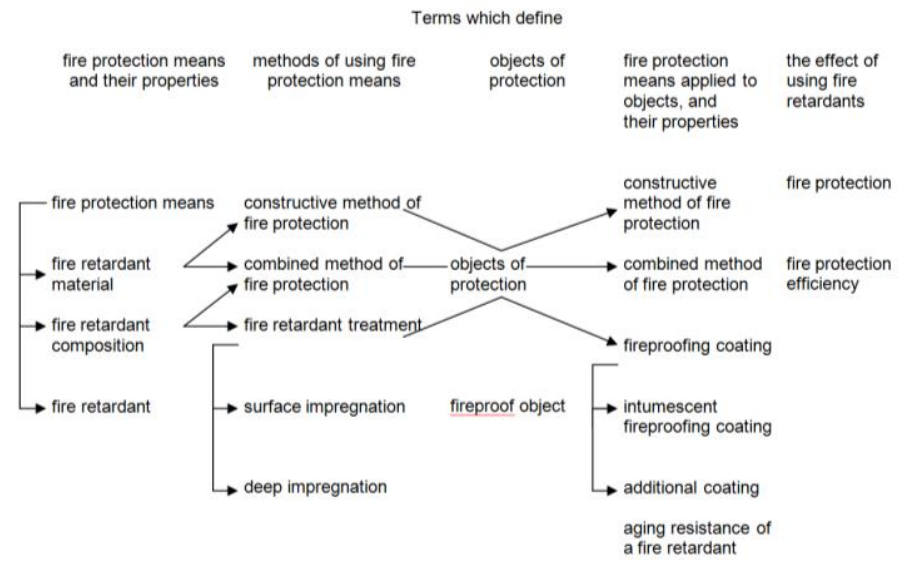

Fig. 1. Schematic representation of a terminological system

In the left column of the diagram, there are terms denoting the types of fire protection means with the relationship between them established based on the classification. The horizontal links indicated in the diagram illustrate the relationship between the terms corresponding to the concepts which denote products, the technology of its application and the result of application and related to one of the types of fire protection means.

When combining the terms in the scheme, the requirements specified above are fully observed. Each term occupies a specific and unique place in the scheme and only one term corresponds to each position, which expresses an unambiguous relationship between the term and the concept and the absence of synonymy.

When eliminating ambiguity in the definitions of terms, a wording was chosen, the use of which would contribute to increasing its meaning from the terminological system. For example, in different documents the term "fire protection" is defined as:

- a technical measure aimed at increasing the fire resistance and / or reducing the fire hazard of buildings, structures, building structures [19], i.e. technological process, method;

- the type of passive protection against ignition and fire [20], i.e. the result of this process, the composition applied to the structure, the assembled material; 
- reducing the fire hazard of materials and structures by special processing [21], i.e. achieved effect.

Obviously, this term in the first two meanings can be, depending on the context, replaced by some other term (group of terms), located respectively in the second or fourth columns of the diagram, while in the meaning of the effect of reducing the fire hazard, this term doesn't have any substitutes close in meaning.

The embedding of existing terms in the scheme required an assessment of their definitions on the basis of the relationships established in it. So, in the definitions presented in each of the standards containing requirements for fire protection means for wooden, metal structures and electrical cables and methods of their testing, definitions of the concept of "fire retardant efficiency" are identified with experimentally determined indicators [19, 22, 23]. As a result, essentially one concept was divided into three components, focused on the corresponding field of application of the fire protection means, each of which is expressed by its own term. In this interpretation, the definition of the term is related to the test method. Therefore, the number of definitions of the concept must correspond to the number of methods, which may not be limited to the specified value. This approach blurs the content of the concept, which can be clearly formulated if it is assumed that the concept does not mean an experimentally determined indicator, but the general ability of fire protection means to reduce the fire hazard of protected structures and materials, assessed by comparing the level of this hazard before and after their use. This means a significant reduction in fire hazard, accompanied by a qualitative change in the state of the protected object in this regard. This understanding of the content of the concept corresponds to the following formulation of its definition: "fire retardant efficiency is the ability of substances, compositions, materials and products to reduce the fire hazard of a fire protection object and / or increase its fire resistance to a certain level." Then the above experimentally determined indicators (loss of weight of a sample of fire-retardant wood, the time to reach the critical temperature of a standard sample of a steel structure with a fire-retardant coating, the length of the flame-damaged (charred) will be the means of expressing this ability, allowing for its quantitative assessment.

Another example is related to the use of the term "constructive fire protection", which serves to classify the fire protection means applied to structures and materials when establishing the permissible scope of their application. They, opposing the term "intumescent fire retardant coating", denote the result of the use of non-intumescent fire retardants and various building materials. However, in this case, the requirement for the correspondence of the meaning of the term to the expressed concept is violated, since the feature that unites fire retardants and building materials into one concept - the absence of swelling during thermal (fire) exposure - is not reflected in the name of the term. On the other hand, the term "constructive fire protection" denotes a derivative of the concept of "construction", in technology means the device of an object, or the object itself with such a device, which provides for the relative position of parts of the object, the way of their connection and interaction [24]. In construction, this concept means an organized set of structural elements with a certain rigidity [25]. Based on the above definitions, it can be stated that the structure is a heterogeneous formation in which individual parts can be distinguished. As it follows, the term "structural fire protection" can only be applied to assembled building materials, which are actually a structure, but not to fire protection coatings, which are basically a homogeneous layer of material. The definition of the term should also include fire retardant materials, which are generally the same type of product as building materials. In this sense, the term is logically embedded in the scheme as an element in the sequence of terms "fireretardant material" $\rightarrow$ "constructive method of fire protection" $\rightarrow$ "constructive fire protection" with the following definition: "constructive fire protection is construction or fireretardant materials mounted on an object". 


\section{Conclusion}

The compiled diagram with the relationships between the terms marked on it can be used to demonstrate the permissible combinations of terms when used together. The lack of links in the diagram between the terms "fire retardant treatment" and "fire retardant material", "fire retardant coating" and "fire retardant material" indicates that one should avoid the wording "treatment of structures with fire retardant materials" or "use of fire retardant materials to obtain fire retardant coatings." Fire-retardant materials, in contrast to fire-retardant compositions, mean finished piece products in the form of sheet, roll, profile and other similar materials that are attached (mounted) to the protected structures and, therefore, the combination of the term designating them with the term "fire retardant treatment" is incorrect. Coating in construction means a layer of material applied to a structure and carrying a specific function [25]. Accordingly, the term "fire retardant coating" is defined as a layer on the surface of an object resulting from the application of a fire retardant composition. Since when using fire-retardant materials, it is allowed or provided for the presence of gaps and voids between the mounted material and the surface, the result of their use, in general, can't be considered as a fire-retardant coating.

The considered method of systematization of terms allows, on the basis of simple and understandable signs of their distribution in the system, to obtain an ordered set of unambiguously defined and agreed terms. The drawn up scheme can be assessed as a variant of the terminological system in the field of fire protection. Technology of intumescent compositions and the process of intumescence itself contains lots of unsolved issues. One of them concerns the assessment of charred layers properties in non-specific (laboratory) conditions; such task requires some express-methods which, although, have to provide repeatable data.

\section{References}

1. V.V. Vinogradov, Russian language. Grammar teaching about the word, Moscow, 1986, p.20.

2. Arnold I.V, Lexicology of modern English: Textbook for universities, Moscow, 1986, p. 229.

3. R 50.1.075-2011, Development of standards on terms and definitions, p.5.

4. GOST R ISO 704-2010, Terminology work. Principles and methods, p.19

5. A. Ustinov, O. Zybina, L. Tanklevsky, V. Lebedev, A. Andreev, Intumescent coatings with improved properties for high-rise construction, E3S Web Conf. 33, 02039 (2018).

6. V. Prusakov, Gravit M., Simonenko Y., Minnullina A., Artyukhina A., Fire retardant for expansion and linear joints in buildings and tunnels, MATEC WEB OF CONFERENCES, 2018.

7. T. Eremina, Korolchenko, D., Fire protection of building constructions with the use of fire-retardant intumescent compositions, Buildings, 2020, 10(10), стр. 1-14, 185.

8. A. Ustinov, O. Zybina, A. Tomakhova, S. Pavlov, The enhancement of operating properties of intumescent fire-protective compositions, MATEC Web Conf. 245, 11008 (2018).

9. M.V. Gravit, Serdjuks, D., Bardin, A.V., Prusakov, V., Buka-Vaivade, K., Fire Design Methods for Structures with Timber Framework. Magazine of Civil Engineering, 2019, 85(1), P. 92-106.

10. T.Yu. Eremina, Korolchenko, D.A., Kuznetsova, I.N., Comprehensive assessment of fire protective intumescent paint terma, Journal of Physics: Conference Series, 2020, 
1425(1), 012099.

11. M.V. Gravit, Golub, E.V., Grigoriev, D.M., Ivanov, I.O., Fireproof suspended ceilings with high fire resistance limits. Magazine of Civil Engineering, 2018. 84(8). Pp. 75-85.

12. M. Nikitina, A. Ustinov, V. Kiseleva, I. Babikov, New fire retardant compositions for fire-resistant automatic curtains, MATEC Web Conf. 245, 11004 (2018).

13. T.Yu. Eremina, Korolchenko, D.A., Kuznetsova, I.N., Synergism of physical and chemical processes in intumescent fire-retardant paints, IOP Conference Series: Materials Science and Engineering, 2020, 960(3), 032037.

14. A. Ustinov, Zybina, O., Andreev, A., On the impact caused by titanium dioxide of different trademarks on the properties of Intumescent fire-protective coatings, International Scientific Conference on FarEastCon, ISCFEC. Vladivostok, 2018. 945. P. 212-217.

15. M. Morys, Illerhaus B., Sturm H. and Schartel B., Variation of Intumescent Coatings Revealing Different Modes of Action for Good Protection Performance, Fire Technology 53 (4), 2017.

16. T. Eremina, Nesterov, M., Korolchenko, D., Giletich, A., Problematic issues of quality, certification and tests of fire-fighting technical production, E3S Web of Conferences, 2020, 164, 14023.

17 T. Eremina, Korolchenko, D., Portnov, F., Methodology for optimizing the study of fire-retardant compositions for building materials and structures, IOP Conference Series: Materials Science and Engineering, 2020, 1001(1), 012018.

18 M. Morys, Illerhaus B., Sturm H. and Schartel B., Size is not all that matters: Residue thickness and protection performance of intumescent coatings made from different binders, Journal of Fire Sciences 35 (2), 2017.

19 GOST R 53295-2009 Fire retardant compositions for steel constructions. General requirement. Method for determining fire retardant efficiency.

20 Fire safety. Encyclopedia. 5th ed., Rev. and add. Moscow: FGBU VNIIPO EMERCOM of Russia, 2017, 582 p.

21. GOST 12.1.033-81.Occupational safety standards system. Fire safety.Terms and definitions.

22. GOST R 53292-2009 Fire retardant compositions and substances for wood. General requirements. Test methods.

23. GOST R 53311-2009 Fire retardant cable coatings. Methods for determination of fireproof efficiency.

24. Great Soviet Encyclopedia, third edition, M.,: Soviet Encyclopedia, 1973.

25. GOST R 58033-2017 Buildings and civil engineering works. Vocabulary. Part 1. General terms. 